\title{
Histamine Detection in Mackerel (Scomberomorus Sp.) and its Products Derivatized with 9-Flourenilmethylchloroformate
}

\author{
Muhammad Abdurrahman Munir ${ }^{1,2}$, Lee Yook Heng ${ }^{1}$, Edison Eukun Sage ${ }^{1}$, \\ Muhammad Mukram Mohamed Mackeen ${ }^{1}$ and Khairiah Haji Badri ${ }^{1}$ \\ ${ }^{1}$ Department of Chemical Sciences, Faculty of Science and Technology, Universiti Kebangsaan Malaysia, \\ Bangi, Selangor. \\ ${ }^{2}$ Department of Pharmacy, Faculty of Health Science, Universitas Alma Ata, Bantul, Yogyakarta. \\ *Corresponding Author Email: kaybadri@ ukm.edu.my \\ Received 02 November 2020, Revised 23 June 2021, Accepted 13 September 2021
}

\begin{abstract}
Histamine is commonly present in food containing proteins, like in mackerel. Consuming fish is imperative for the improvement of human muscles. Nevertheless, some studies reported ingesting fish containing histamine more than $50 \mathrm{mg} \cdot \mathrm{kg}^{-1}$ can cause toxicity. This study analyzed and determined the composition of histamine in mackerel and its products commonly consumed in Malaysia, especially on the East Coast of Malaysia. These included processed mackerel such as canned products, satay (skewed fish) and keropok lekor (fish cake/ cracker). Histamine analysis was performed using High Performance Liquid Chromatography (HPLC) equipped with a fluorescence detector. A derivatizing reaction was applied to increase the sensitivity of HPLC to histamine using 9-flourenilmethylchloroformate (FMOC-Cl). The chromatographic separation was achieved in $15 \mathrm{~min}$. Method validation was in accordance to Commission Decision 657/2002/CE. The linear range was at $0.16-5.00 \mu \mathrm{g} \cdot \mathrm{mL}^{-1}$ (histamine) with the LOD at $0.10 \mu \mathrm{g} \cdot \mathrm{mL}^{-1}$ and LOQ at $0.30 \mu \mathrm{g} \cdot \mathrm{mL}^{-1}$. Method applicability was checked on seven real samples involving raw, cooked, and dry products, yielding acceptable recovery.
\end{abstract}

Keywords: Histamine, Mackerel, HPLC, Validation, LOD, LOQ

\section{Introduction}

An increase in the number of food types and their products are produced and distributed for human consumption. Nevertheless, several problems still exist for many years in relation to consumers' health, such as heavy metals, usage of pesticides, and traces of toxic compounds such as biogenic amines that are commonly detected in fish [1] and fish products. Biogenic amines are simple nitrogen compounds that generally can be found in food and beverages containing protein such as fish, meat, cheese, milk, and others. The main biogenic amines present in these products are putrescine, tyramine, cadaverine, and histamine [2]. They are produced by amination and/or transamination of aldehydes and ketones. They can also be formed by decarboxylation of free amino acids (Fig. 1) during the degradation process of proteinbased food and beverages involving specific bacteria such as Lactobacillus, Pediococcus, and Leuconostoc species. The determination of biogenic amines in fish is of great interest simply because of their toxicity besides being used as an indicator for quality [3] or freshness or even spoilage level of fish [4]. 

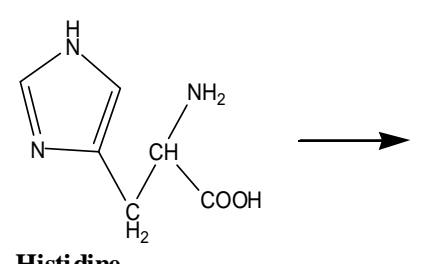

Histidine

Figure 1. Production of histamine from its corresponding decarboxylation of amino acids

Among all biogenic amines found in food, histamine is considered toxic and easily present in food and beverages, as informed by The European Food Safety Authority [5-6]. According to Food and Drug Administration (FDA), the acceptable amount of histamine that can be consumed is below $50 \mathrm{mg} \cdot \mathrm{kg}^{-1}$. It becomes toxic and leads to several symptoms such as nausea, palpitation, and headache [78] when it goes beyond this level.

Histamine fish poisoning, called scombroid poisoning, is the most general foodborne ailment related to fish consumption $[6,9-10]$. Therefore, the demand for a safer approach to consuming fish and its products has promoted more studies to tackle the histamine issues, especially in detecting its existence.

Several chromatography techniques have been studied in order to determine histamine in fish. These include usage of thinlayer chromatography (TLC), high performance liquid chromatography (HPLC) and gas chromatography (GC). Some researchers use HPLC and GC equipped with mass spectrometry (MS) since MS has some advantages in the selectivity and anti-jamming capability [5, 10-11]. TLC is simple and requires no sophisticated instruments but several studies reported several issues from the longer time needed for analysis, inaccurate acquired results, and more for qualitative demand. Whereas GC is not often applied due to inherent tailing problems. Histamine is a polar and non-vaporized compound, thus the use of derivatization reagent prior to GC analysis is compulsory in order to detect histamine [12-13]. Among these methods, HPLC is the most popular technique used in order to detect histamine in food and beverages, owing to its high selectivity property and simpler than any other method [14-17]. Generally, histamine separation is performed in the $\mathrm{C} 8$ or $\mathrm{C} 18$ column, in gradient elution with the mobile phase consisting of methanol, acetonitrile, or water [18].

Extraction is the most critical step in the histamine detection procedure. According to some studies, the extraction method can influence analytical recovery. The extraction of histamine from a solid sample such as fish and meat is usually carried out using an acid such as hydrochloric acid ( $\mathrm{HCl})$, perchloric acid $\left(\mathrm{HClO}_{4}\right)$, or trichloroacetic acid (TCA) [19]. Biogenic amines are strong organic bases, thus it is important to take advantage of this feature for their separation from the sample matrix, where TCA represented a better choice for fish $[12,20]$. Due to the structural characteristic of histamine, the derivatization step is an imperative step, and several reagents are applied such as $O$ phthaldialdehyde (OPA), dansyl chloride, dansyl chloride and 9-flourenilmethylchloroformate (FMOC-Cl) [21].

Fish mackerel is widely consumed all over the world due to its nutritional values. Furthermore, monitoring fish freshness is imperative to ensure the safety of human consumption [22]. Of particular interest are the products of mackerel such as satay, fish ball, or even the popular Malaysia product prepared from mackerel (known locally as "keropok lekor") that is consumed in several countries in South East Asia such as Thailand and Indonesia. There is a lacking of reporting on histamine analysis. Therefore, the aim of the present work was to establish a method for determining histamine in mackerel and its products using HPLC analysis and 
fluorescence as a detector. In this study, FMOC-Cl was used as a derivatizing agent in order to increase the sensitivity and selectivity of histamine (Fig. 2). The proposed method was validated in terms of linearity, accuracy, precision, detection, and quantification limit. Moreover, the developed and validated method was applied to the histamine analysis in mackerel samples.

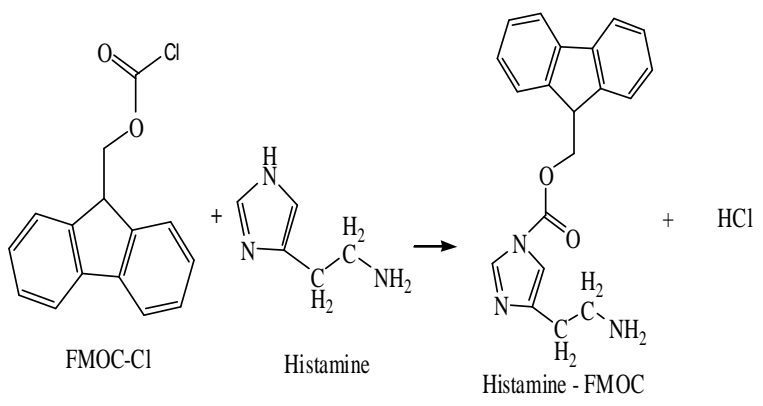

Figure 2: Derivatization of histamine with FMOC-Cl

\section{Materials and Methods Materials}

Histamine dihydrochloride (HIS) was purchased $(\geq 99 \%$ purity) from SigmaAldrich. FMOC-Cl, TCA, HPLC-grade acetonitrile $(\mathrm{ACN})$ and HPLC-grade methanol $(\mathrm{MeOH})$ were also purchased from SigmaAldrich. Hydrochloric acid $(\mathrm{HCl})$, acetone, potassium borate buffer, and glycine were obtained from UKM Laboratory (purchased from Sigma-Aldrich). Standard (stock) solution of histamine was prepared at a concentration of $1000 \mathrm{mg} \cdot \mathrm{L}^{-1}$ in $0.1 \mathrm{M} \mathrm{HCl}$. All chemicals and reagents used were of analytical grade.

\section{Preparation of standard solution}

A stock solution of histamine was prepared with $0.1 \mathrm{M} \mathrm{HCl}$ in a volumetric flask. The solution was stored at $4^{\circ} \mathrm{C}$. Standard solutions were prepared by diluting the stock solution in order to construct the calibration curve $\left(0.16-5 \mu \mathrm{g} \cdot \mathrm{mL}^{-1}\right)$.

\section{Sample preparation}

About $5 \mathrm{~g}$ of fresh fish sample in wet condition was placed in a beaker and homogenized with $10 \mathrm{~mL}$ of $10 \%$ TCA for 20 $\min$. The slurry was then centrifuged for $5 \mathrm{~min}$ at $2000 \mathrm{rpm}$. The supernatant was filtered through a filter paper and rinsed with $10 \%$ TCA. The sample was derivatized using $5 \mathrm{mM}$ FMOC-Cl. The homogenate was stored at $4^{\circ} \mathrm{C}$ before further analysis using HPLC-FD.

\section{Derivatization procedure}

$10 \mu \mathrm{L}$ of the sample was mixed with $20 \mu \mathrm{L}$ of $\mathrm{FMOC}-\mathrm{Cl}(5 \mathrm{mM})$ and $10 \mu \mathrm{L}$ of potassium borate buffer in a vial. The mixture was incubated at $10^{\circ} \mathrm{C}$ for $20 \mathrm{~min}$. The supernatant was then mixed with $10 \mu \mathrm{L}$ of 0.1 $\mathrm{M}$ glycine. Finally, $950 \mu \mathrm{L}$ of $50 \%$ acetonitrile was added to the mixture before further analysis using HPLC-FD.

\section{HPLC - FD Detection of Histamine}

The HPLC analysis was carried out on a Waters 2475 - C18 column $(150 \mathrm{~mm} \times 2.1$ mm ID, $3 \mu \mathrm{m}$ particle size), equipped with a fluorescence detector (ex: 267/ em: 314). Chromatographic separation was carried out using an isocratic elution. The mobile phase was acetonitrile: deionized water $(63: 37, \mathrm{v} / \mathrm{v})$, and the flow rate was kept at $0.34 \mathrm{~mL} \cdot \mathrm{min}^{-1}$ with the injection of $0.5 \mu \mathrm{L}$. The mixture was filtered using a membrane filter $(0.45 \mathrm{~nm})$ and degassed in an ultrasonic bath for $10 \mathrm{~min}$ before being analyzed. The target compound was identified according to the retention time of its corresponding standard. Quantification was measured using the standard's calibration curves that underwent a similar derivatization step of sample preparation.

\section{Validation Study}

All analytes injected were performed in triplicate to ensure accuracy, precision, 
recovery, detection, and quantification threshold limit. The correlation coefficient and linear regression studies, repeatability assessment, mean measurement, standard, and relative standard deviation were calculated using Microsoft Excel 2019 software.

\section{Results and Discussions Histamine Extracted from Fish Sample}

Extraction of histamine from fish samples is an imperative step before analysis using HPLC Histamine is one of the biogenic amines and has a diverse chemical structure, and occur at a wide range of concentration in food and beverage samples [11]. Most of the extraction methods reported in the literature for histamine detection were generally using the acidic extraction method, starting with a solid matrix. Organic solvents such as methanol and ethanol are rarely used. The choice of acid must be related to the sample characteristics. Several compounds other than histamine might be disturbances and can be eliminated in this step. $\mathrm{HCl}$ becomes a good choice for cheese and fruits analysis but is not suitable for meat and fish owing to the difficulties related to occasional sample turbidity [12]. In this study, histamine in fish samples extracted with the use of TCA is the best choice due to its efficacy to precipitate amino acids from the fish sample.

\section{Method Validation}

The analytical method was optimized by determining the linear range, precision, recovery detection and quantification threshold limit. Results are presented in Table 1. Linearity of the calibration curves was established by injecting six standard mixtures with concentrations ranging from 0.16 to $5 \mu \mathrm{g} \cdot \mathrm{mL}^{-1}$. A series of standard working solutions at $0.16,0.31,0.63,1.25$, 2.50 and $5 \mu \mathrm{g} \cdot \mathrm{mL}^{-1}$ were obtained from optimized conditions. Satisfactory linearity was acquired between the peak area and concentration of the analyte (Fig. 3). The detection limit was validated from the lowest concentration of histamine required to give a signal to noise ratio of three $(\mathrm{S} / \mathrm{N}=3)$, while the quantification limit was validated with a signal to noise ratio of $10(\mathrm{~S} / \mathrm{N}=10)$. Both of them were reflected by the limit of detection (LOD) and limit of quantification (LOQ) values $[10,23]$.

Table 1. Linear range, calibration curve, correlation coefficient (R), detection and quantification limit of histamine.

\begin{tabular}{lc}
\hline Parameters Validated & Results \\
\hline Linear range $\left(\mu \mathrm{g} \cdot \mathrm{mL}^{-1}\right)$ & $0.16-5$ \\
Calibration curve & $\mathrm{y}=4 \mathrm{E}+06 \mathrm{x}+175075$ \\
$\mathrm{R}^{2}$ & 0.9998 \\
$\mathrm{LOD}\left(\mu \mathrm{g} \cdot \mathrm{mL}^{-1}\right)$ & 0.10 \\
$\mathrm{LOQ}\left(\mu \mathrm{g} \cdot \mathrm{mL}^{-1}\right)$ & 0.30 \\
Intraday $(\% \mathrm{RSD})$ & 1.73 \\
Interday $(\% \mathrm{RSD})$ & 7.38 \\
Recovery $(\%)$ & 103 \\
\hline
\end{tabular}

R2: square of regression coefficient; tR: retention time; LOD: limit of detection; LOQ: limit of quantification; RSD: relative standard deviation.

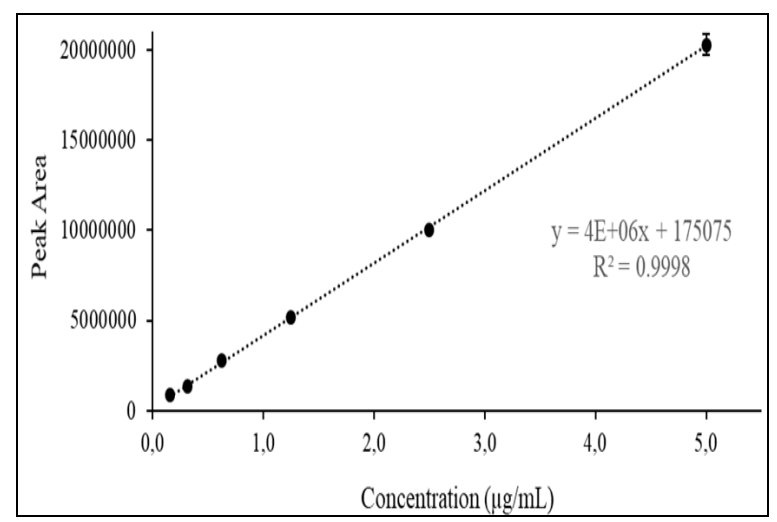

Figure 3. Calibration curve of histamine - FMOC, peak area versus concentration

The repeatability and reproducibility of the method were measured by injecting histamine standard at six replicates on the same day (intraday) and over ten days (interday), respectively. Good reproducibility of both the peak area (RSD $\leq 1.73 \%$ ) for 
intraday and (RSD $\leq 7.38 \%)$ for inter-day, they are presented in Table 1 .

Various studies have reported the application of other derivatizing reagents such as OPA and dansyl chloride. Both reagents are generally applied to derivatize biogenic amines before analyzing with HPLC, nevertheless, compared to FMOC - $\mathrm{Cl}$, they have several drawbacks. OPA cannot derivatize primary amine, and derivatization to primary and secondary amines are unstable, while dansyl chloride upon application is time - consuming and needs to be heated to high temperature in order to complete the derivatization process [24, 25]. The selectivity of FMOC - $\mathrm{Cl}$ was reported by Ramachandra et al., after derivatized using FMOC, the analyte can be detected using HPLC equipped with UV and FL detectors at the picomole level. The stability of FMOC $-\mathrm{Cl}$ is better than OPA [26]. In terms of reactivity toward nucleophiles, FMOC $-\mathrm{Cl}$ is also better than OPA. Moreover, the application of acid solvents such as TCA and $\mathrm{HCl}$ in this research to dilute histamine is satisfactory. The products have a better collision-induced dissociation (CID) energy, which will provide a straightforward way to identify the reactive amines by applying MS/MS analysis [27].

After ten days, histamine derivatized with FMOC-Cl has degraded owing to several factors such as temperature and the condition of the environment. FMOC-Cl composition inside histamine is possible to reduce if exceed more than ten days. A mackerel sample was selected to conduct the precision and accuracy assay. The intraday precision was measured from the result of six replicated analytes prepared at $5 \mu \mathrm{g} \cdot \mathrm{mL}^{-1}$ of histamine standard to fish sample in a single day, whereas the inter-day precision was determined from the analytes for ten consecutive days. The mixture was derivatized prior to HPLC analysis. Satisfactory recovery for histamine was acquired (103\%) (Table 1). It can be concluded that (TCA) can be applied to extract histamine from fish and its products.

\section{Analysis of Mackerel}

The established and validated method was adopted to determine the histamine concentration in fish samples. In histamine analysis of fish mackerel and its products, peak identification of each sample was identified on the basis of retention time by comparing with standard solutions. It was also confirmed by spiking standards to the fish samples. The retention time of histamine was predetermined and detected to be stable and consistently reproducible.

Quantification was based on the external standard method using calibration curves fitted by linear regression analysis. During the experimental conditions, baseline separation of histamine was obtained in less than $15 \mathrm{~min}$. No interference peaks were presented at the retention times of the analyte (Fig. 4). This method was applied for histamine detection in 7 different products of mackerel. The samples tested and the concentration found of the histamine are shown in Table 2.

Table 2. Histamine concentration in mackerel and its products $(\mathbf{n}=6)$.

\begin{tabular}{lc}
\hline \multicolumn{1}{c}{ Sample type } & Histamine $\left(\mathbf{\mu g} \cdot \mathbf{k g}^{-\mathbf{1}}\right)$ \\
\hline Mackerel fish & 1.16 \\
Canned mackerel & 0.28 \\
Fish ball mackerel & 0.53 \\
Fish satay mackerel & 0.19 \\
Keropok lekor (mackerel cracker) & 0.84 \\
Fish chip mackerel & 0.17 \\
Salted mackerel & 0.03 \\
\hline
\end{tabular}

Several studies have been carried out in order to verify the presence of histamine derivatized with FMOC-Cl. According to (Fig. 4a), three components appeared at a $2.080,3.510$ and $3.839 \mathrm{~min}$ retention time. 
The peak for the derivatized histamine standard appeared at a retention time of 2.080 min. The peak for FMOC-Cl was detected at $5.380 \mathrm{~min}$, glycine appeared at $4.310 \mathrm{~min}$, and TCA appeared at $3.344 \mathrm{~min}$. Analysis of FMOC-Cl and $\mathrm{HCl}$ has also been studied where the retention time of $\mathrm{HCl}$ and TCA is almost similar. The fish samples have successfully been derivatized using FMOC-Cl, where TCA was used to extract histamine in the fish prior to derivatization. The detected histamine appeared at $2.188 \mathrm{~min}$, and it was similar to the histamine standard, as shown in (Fig. 4b).

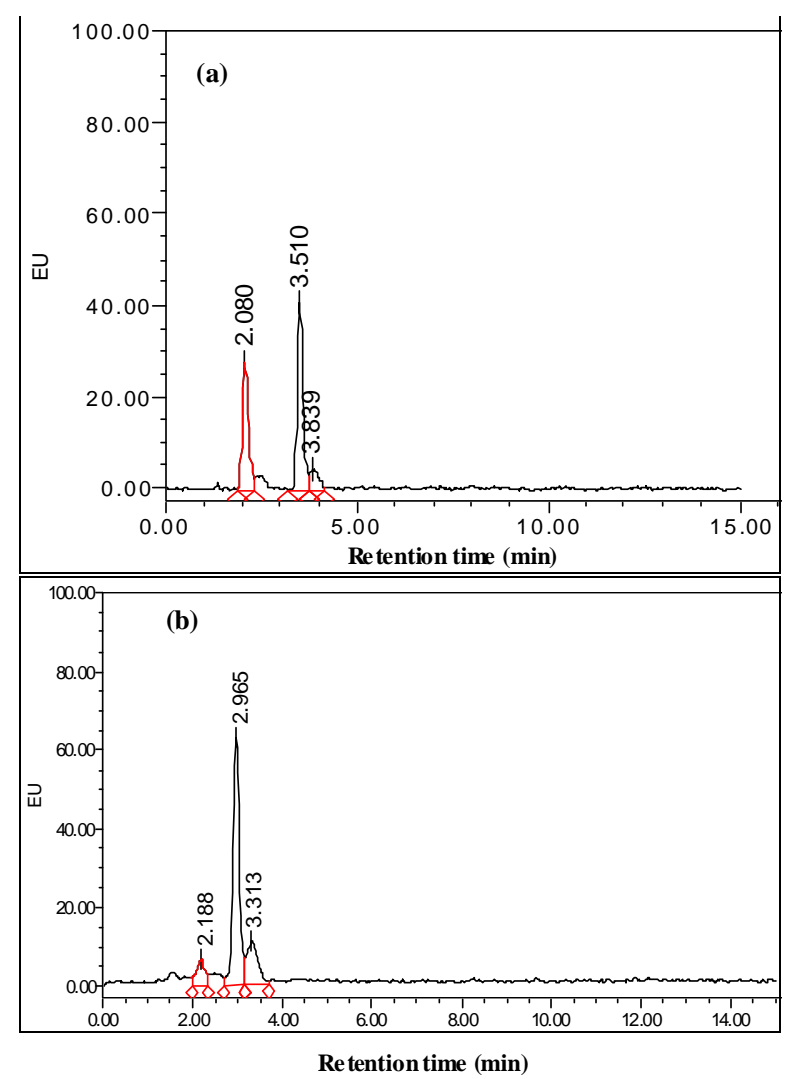

Figure 4. (a) The chromatogram of histamine standard derivatized by FMOC-Cl (ex: 267/ em: 314) and (b) the chromatogram of mackerel derivatized with FMOC-Q (ex: 267/ em: 314)

Fish and fish products contain histamine at various concentrations. The concentration of histamine is influenced by several factors, such as the presence of bacteria. Bacterial growth in fish and fish products results in a shelf life reduction of the fish and fish products, furthermore an increase in the risk of fish-borne diseases [28]. Yusoff et al. also reported that the content of histamine is influenced by the storage time due to microbial activity [29]. Some other studies related to histamine detection in food samples are on different approaches to analysis. Zhai et al. detected histamine in canned sardines at $7.5 \mathrm{mg} \cdot \mathrm{kg}^{-1}$ [30], while Parchami et al. acquired histamine at 0.104 $\mathrm{mg} \cdot \mathrm{kg}^{-1}$ in fish samples [31]. Francisco et al. studied histamine detection using UV and fluorescence detectors and found histamine below the FDA regulation limit and detection limit at 0.17 and $1.6 \mathrm{mg} \cdot \mathrm{kg}^{-1}$, respectively [32]. Kounnoun et al. used OPA as a reagent to derivatize histamine and later analysed using HPLC equipped with UV and FL detectors. Histamine in fish samples was detected at below $25 \mathrm{mg} \cdot \mathrm{kg}^{-1}$ and detection limit of $1.8 \mathrm{mg} \cdot \mathrm{kg}^{-1}$ [33]. Zhu et al. reported the application of HPLC to analyse histamine after derivatization with a fluorogenic compound with a detection limit at 1.3 $\mathrm{nmol} \cdot \mathrm{L}^{-1}$ [34]. Chong et al. reported that sardine was the only fish where histamine still could be analyzed under $4{ }^{\circ} \mathrm{C}$ during the degradation process [35]. Therefore, a reliable method is needed in order to detect histamine in food to prevent fish-borne intoxication, maintain good control of fish production and check safety quality. In this study, HPLC is reliable to analyze histamine in the fish samples [36].

According to the findings in this study, the concentration of histamine in mackerel and its products can be categorized safe and can be consumed since the histamine concentrations were at a lower level following the Compliance Policy Guideline. This guideline suggests that if histamine level is at $10 \mathrm{mg} \cdot \mathrm{kg}^{-1}$, it is considered not toxic, nevertheless, the concentration at $30 \mathrm{mg} \cdot \mathrm{kg}^{-1}$ is considered as decay, whereas above $30 \mathrm{mg}$. $\mathrm{kg}^{-1}$ indicates the fish is totally decomposed 
[37]. Histamine poisoning generally occurred upon improper consumption of Scombroid fish species such as tuna, bonito, saury and mackerel. They have a high level of histidine in their flesh [38]. However, fish and fish products are necessary for humans. Nevertheless, the quality of fish and fish products is more difficult to control than meat owing to the quality of them influenced by several parameters such as species, age, habitats and enzymes activity [39].

Various concentrations of histamine are regulated in different countries. FDA has issued an approved level of $50 \mathrm{mg} \cdot \mathrm{kg}^{-1}$, while a higher concentration of histamine is allowed by the European Community, South Africa, and Italy at $100 \mathrm{mg} \cdot \mathrm{kg}^{-1}$. Australia and Germany suggested a much higher histamine level at $200 \mathrm{mg} \cdot \mathrm{kg}^{-1}$ [40].

\section{Conclusion}

This study indicated that the developed derivatization method was suitable for histamine determination in mackerel and its by-products using HPLC-FD chromatographic technique. The chromatographic separation was achieved within $15 \mathrm{~min}$, and satisfactory peak resolution was acquired. The FMOC-Cl reaction was carried out at ambient temperature. The method was reproducible and accurate, with recovery at $103 \%$. Using this method, we were able to detect and monitor histamine in the fish sample. Though there are zero cases of histamine poisoning reported during the consumption of mackerel and its by-products in Malaysia, and although histamine concentration is low in these fish products, this technique is handy in offering a trustable quantified result.

\section{Acknowledgments}

The authors would like to extend their gratitude to Universiti Kebangsaan Malaysia and Malaysia Ministry of Education for providing the necessary funding for this research through the Research Incentive Grant (GGP-2019-021).

\section{Conflict of Interest}

The authors declare that they have no conflict of interest in any parts of this article to any concerned party.

\section{References}

1. M. Papageorgiou, D. Lambropoulou, C. Morrison, E. Klodzinska, J. Namiesnik and J. Plotka - Wasylka, Trac - Trend Anal. Chem., 98 (2017) 128. doi: 10.1016/j.trac.2017.11.001

2. M. A. Sahudin, M. S. Su'ait, L. L. Tan, L. H. Heng and N. H. A. Karim, Anal. Bioanal. Chem., 411 (2019) 6449. doi.org/10.1007/s00216-019-02025-4

3. L. Pester, Food Addit. Contam. A, 28 (2011) 1547. doi: 10.1080/19440049.2011.600728

4. Y. Q. Wang, D. Q. Ye, B. Q. Zhu, G. F. $\mathrm{Wu}$ and C. Q. Duan, Food Chem., 163 (2014) 6.

doi.org/10.1016/j.foodchem.2014.04.064

5. C. I. G. Tuberoso, F. Congiu, G. Serreli, S. Mameli, Food Chem., 175 (2015) 29. doi: 10.1016/j.foodchem.2014.11.120

6. R. Parchami, M. Kamalabadi and N. Alizadeh, J. Chromatogr. A, 1481 (2017) 37.

doi: 10.1016/j.chroma.2016.12.046

7. Food and Drug Administration, Scombrotoxin (histamine) formation. In fish and fishery products hazards and controls guide, $4^{\text {th }} \mathrm{Ed}$. Office of Seafood, Washington DC (2011).

8. C. Proestos, P. Loukatos and M. Komaitis, Food Chem., 106 (2008) 1218. doi.org/10.1016/j.foodchem.2007.06.048

9. M. Trevisani, R. Mancusi, R, M. Cecchini, C. Costanza and M. Prearo, Vet. Sci., 4 (2017) 31. 
doi: 10.3390/vetsci4020031

10. Y. Fu, Z. Zhou, Y. Li, X. Lu, C. Zhao and G. Xu, J. Chromatogr. A, 1465 (2016) 30. doi.org/10.1016/j.chroma.2016.08.067

11. A. Jain, M. Gupta and K. K. Verma, $J$. Chromatogr. A, 1442 (2015) 60. doi.org/10.1016/j.chroma.2015.10.036

12. E. Dadakova, M. Krizek and T. Pelikanova, Food Chem., 116 (2009) 365. doi.org/10.1016/j.foodchem.2009.02.018

13. S. Bomke, B. Seiwert, L. Dudek, S. Effkemann and U. Karst, Anal. Bioanal. Chem., 393 (2009) 246. doi: 10.1007/s00216-008-2420-2

14. H. Dong and K. Xiao, Food Chem., 229 (2017) 502. doi.org/10.1016/j.foodchem.2017.02.120

15. J. J. Zhong, N. Liao, T. Ding, X. Ye and D. H. Liu, J. Chromatogr. A, 1406 (2015) 331. doi.org/10.1016/j.chroma.2015.06.048

16. A. M. Piaste, A. Jastrzebska, M. P. Krzeminski, T. M. Muziol and E. Szlyk, Anal. Chim. Acta, 834 (2014) 58. doi.org/10.1016/j.aca.2014.05.028

17. R. Mandrioli, L. Mercolini and M. A. Raggi, Anal. Bioanal. Chem., 405 (2013) 7941. doi: 10.1007/s00216-013-7025-8

18. C. Lanfranco, S. Moret and G. Purcaro, HPLC in food analysis, CRC Press, Boca Raton (2008).

19. M. A. Munir and K. H. Badri, J. Anal. Methods Chem., 2020 (2020) 1. doi.org/10.1155/2020/5814389

20. C. A. Lazaro and C. A. Conte - Junior, Bra. J. Vet. Res. Animal Sci., 50 (2013) 430.

doi.org/10.11606/issn.16784456.v50i6p430-446

21. Y. Y. Guo, Y. P. Yang, Q. Peng and Y. Han, Food Sci. Technol. Int., 50 (2015) 1523.

doi.org/10.1111/ijfs.12833
22. F. F. Faizal, L. L. Tan and S. I. Zubairi, Sensor Actuat. B - Chem., 269 (2018) 36. doi.org/10.1016/j.snb.2018.04.141

23. S. Jia, Y. Ryu, S. W. Kwon and J. Lee, J. Chromatogr. A, 1282 (2013) 1. doi.org/10.1016/j.chroma.2013.01.041

24. Y. Gao, J. Tan, J. Lu, Z. Sun, Z. Li, Z. Ji, S. Zhang and J. You, Anal. Bioanal. Chem., 412 (2020) 8339. doi.org/10.1007/s00216-020-02969-y

25. X. Huang, Q. Zhang, X. Li, X. Ao and X. Wang, Chromatographia, 84 (2021) 463. doi.org/10.1007/s10337-021-04020-3

26. R. A. Ramachandra, V. Murugan and K. B. Premakumari, J. Appl. Pharm. Sci., 10 (2020) 31 . doi.org/10.7324/JAPS. 2020.10505

27. A. Lkhagva, C. C. Shen, Y. S. Leung and H. C. Tai, J. Chromatogr. A, 1610 (2020) 60536. doi.org/10.1016/j.chroma.2019.460536

28. B. Kuswandi, A. J. Restyana, A. Abdullah, L. Y. Heng and M. Ahmad, Food Control., 25 (2012) 184. doi.org/10.1016/j.foodcont.2011.10.008

29. M. N. M. Yusoff, M. H. Jaffri and S. Azhari, Malays. J. Sci. Health Tech., 7 (2020) 53. doi.org/10.33102/mjosht.v7i.108

30. H. Zhai, X. Yang and L. Li, Food Control, 25 (2012) 303. doi.org/10.1016/j.foodcont.2011.10.057

31. R. Parchami, M. Kamalabadi and N. Alizadeh, J. Chromatogr. A, 1481 (2017) 37. doi.org/10.1016/j.chroma.2016.12.046

32. K. C. A. Francisco, P. F. Brandao, R. M. Ramos, L. M. Goncalves, A. A. Cardoso and J. A. Rodrigues, Int. J. Food Sci. Technol., 55 (2019) 1. doi.org/10.1111/ijfs.14300

33. A. Kounnoun, M. El Maadoudi, F. Cacciola, L. Mondello, H. Bougtaib, N. Alahlah, N. Amajoud, A. El Baaboua and A. Louajri, Chromatographia, 83 (2020) 893. 
doi.org/10.1007/s10337-020-03909-9

34. F. Zhu, H. Liu, W. Zhang, C. Du, H. Zhu, $\mathrm{X} . \mathrm{Du}, \mathrm{X} . \mathrm{Hu}$ and Y. Lin, RSC Adv., 11 (2021) 19541. doi.org/10.1039/D1RA01436F

35. C. Y. Chong, F. A. Bakar, R. A. Rahman, J. Bakar and M. Z. Zaman, J. Food Sci. Technol., 51 (2014) 1118. doi.org/10.1007/s 13197-012-0621-3

36. EFSA, EFSA J., 9 (2011) 2393. doi.org/10.2903/j.efsa.2011.2393

37. S. Oguri, M. Enami and N. Soga, $J$. Chromatogr. A, 1139 (2007) 70. doi.org/10.1016/j.chroma.2006.10.077
38. N. Richard, L. Pivarnik, P. C. Ellis and C. Lee, J. AOAC Int., 91 (2008) 768. doi.org/10.1093/jaoac/91.4.768

39. C. M. Keow, F. A. Bakar, A. B. Salleh, L. Y. Heng, R. Wagiran and S. Siddiquee, Int. J. Electrochem. Sci., 7 (2012) 4702.

40. D. Carelli, D. Centonze, C. Palermo, M. Quinto and T. Rotunno, Bionsen. Bioelectron., 23 (2007) 640. doi.org/10.1016/j.bios.2007.07.008 